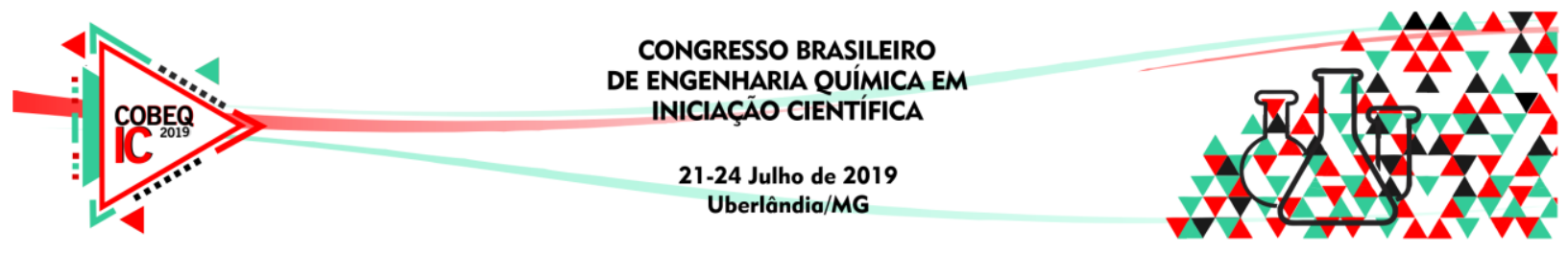

\title{
COMPARISON AND ANALYSIS OF THE EFFECTS OF SEVERAL IMPROVEMENTS IN THE TRADITIONAL MODEL ON ENGINE WORKING WITH OTTO CYCLE
}

\author{
N. P. MERLO ${ }^{1}$, M. A. P. ROCHA ${ }^{1}$, M. R. FRANCO JÚNIOR ${ }^{2}$, B. N. AUD ${ }^{2}$, T. A. L. \\ SILVA $^{2}$, N. R. A. F. ROCHA ${ }^{1}$ \\ ${ }^{2}$ UniRV - Rio Verde University - Fazenda Fontes do Saber - Rio Verde - Goiás Brazil \\ ${ }^{1}$ Post-Graduation Program in Biofuels - UFU - Federal University of Uberlândia Brazil \\ E-mail: moilton@ufu.br
}

\begin{abstract}
Engine performance behavior was investigated by adding some considerations in the usual cycle such as: influence of the temperature in the $k$ coefficient, process gas behaving according to the virial equation and effect of initial temperature of the air. To determine the relationship among independent variables including temperature of the flame, temperature of the flue gas, thermal efficiency and effective average pressure analysis of the some methodologies was used. Comparison between different methodologies shows that the one regarding the virial equation model with influence of temperature in the $k$ coefficient could estimate better thermal efficiency. The results showed that adding and considering the non-idealities of the process became the findings closer to the reality due to thermal efficiency and air temperatures decreased when the real process has to be regarded.
\end{abstract}

\section{INTRODUCTION}

Internal combustion engine (ICE) generate power by converting chemical energy (burning fuel) into heat and then into mechanical work. In an spark ignition port injection (SIPI) engine, a mixture of air and fuel is ignited inside a cylinder by a spark. The efficiency of a modern SIPI engine is limited by a number of factors, including losses by cooling and friction. Typical efficiencies for these engines are on the order of $20 \%$. Characteristics and operation of propulsion systems including ICE are described in many sources (Guibet, 1999; US Dep. Of Energy; Chigier, 1981; Heywood, 1988; Bosh, 2000; Lumley,1999).

Currently, the development of these engines to date has focused on their use with gasoline as the fuel, however, other fuels with suitably high octane numbers, volatility, and other suitable properties (e.g. ethanol and methanol/gasoline blends, CNG, LPG) have been utilized in these engines when modified (e.g. materials, engine design and control) for the particular fuels (Heywood, 1988; Bosh, 2000; Lumley,1999).

Spark ignition direct injection (SIDI) engines may bring a major improvement in SI engines because of their potential reduction in fuel consumption. However, for compliance with stringent emissions standards while performing at high efficiency levels, this engine requires further development, including advanced exhaust treatment and low sulfur fuel compatible with its operating characteristics. Zhao et al., 1999 provide a thorough review of these engines. 


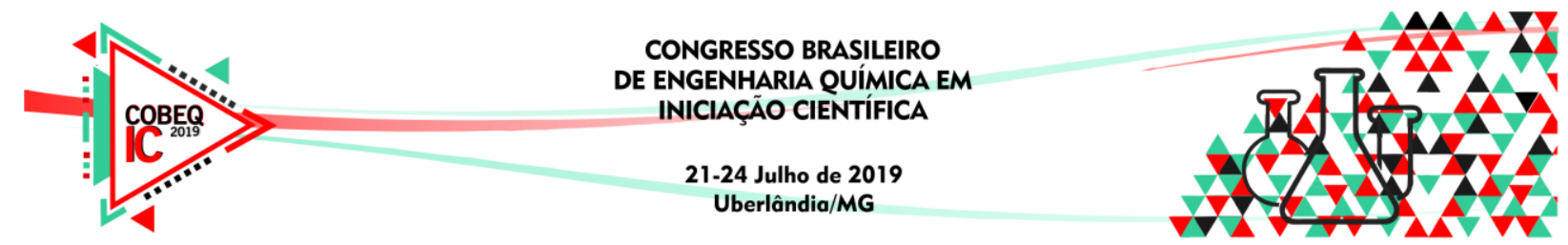

The aims of this study were to review methodological descriptions of the well-known Otto cycle, to discuss how the original methodological approach was applied, and to identify improvements that need to be done by researchers and engineers. An outline of the current equations of Otto cycle and a presentation of the changings proposed in the quantitative methodological research are provided to set the scene for the work.

\section{METHODOLOGY}

Potter and Scott, 2007 considered the control volume is a two state control volume with states for pressure $p$ and temperature $T$. The control volume has a fixed volume $V$ and the change of mass within the control volume is determined by the air mass-flows in and out of the control volume. Within the control volume the energy is conserved and stored. But energy can be transferred to or from the control volume through the air mass-flows in and out or by heat transfer $Q$. Due to difficulties in measuring quantities like energy and mass, it is desirable to express the states for temperature and pressure as differential equations. In the combustion engine, heat $\left(Q_{q}^{\text {air }}\right)$ is added at constant volume while the piston is momentarily at rest at head-end dead center. Then, the First law gives,

$$
Q_{q}^{a i r}=N . C_{v\left(T_{3}, T_{2}\right)}^{a i r}\left(T_{3}-T_{2}\right)
$$

Where $C_{v\left(T_{3}, T_{2}\right)}^{a i r}$ is the molar volume heat of the air calculated by mixing rule found in Poling et al., 2001 and $T_{2}$ and $T_{3}$ are the gas temperature at the inlet and outlet of the compressor, respectively. The rejection of heat $\left(Q_{f}^{\text {air }}\right)$ from the air while the piston is at crank-end dead center can be calculated by the first law as follows,

$$
Q_{f}^{\text {air }}=N \cdot C_{v\left(T_{4}, T_{1}\right)}^{\text {air }}\left(T_{4}-T_{1}\right)
$$

Where $C_{v\left(T_{4}, T_{1}\right)}^{a i r}$ is the molar volume heat of the air calculated by mixing rule found in Poling et al, 2001 and $T_{1}$ and $T_{4}$ are the gas temperature at the intlet and outlet of the scape gases engine system, respectively. Then, the thermal efficiency $(\eta)$ of this cycle is found as follows, assuming constant molar volume heat of air as ideal gas:

$$
\eta=1-\frac{T_{4}-T_{1}}{T_{3}-T_{2}}
$$

The net specific work $\left(W_{c i}\right)$ in a complete cycle is used to define a mean effective pressure $(\bar{P})$,

$$
W_{c i}=\bar{P}(r-1) V_{\min }
$$

Where $r$ is the compression ratio and $V_{\min }$ is the volume of combustion center at the end of the cycle.

Equations of ideal gas for the isentropic process can be considered:

$$
T V^{k-1}=\text { cte } \quad T p^{1-k / k}=\text { cte } \quad p V^{k}=\text { cte }
$$

If the virial equation $[18,19]$ is representing the volumetric gas behavior, then,

$$
\frac{p V}{R T}=1+\frac{B p}{R T}
$$

$B$ is the second virial coefficient that is a function of temperature. Then, the isentropic process has to be represented by the following energy balance:

$$
\frac{C_{v}}{R} \frac{d T}{T}=\frac{T(d B / d T) d V}{(V-B)^{2}}+\frac{d V}{V-B}
$$




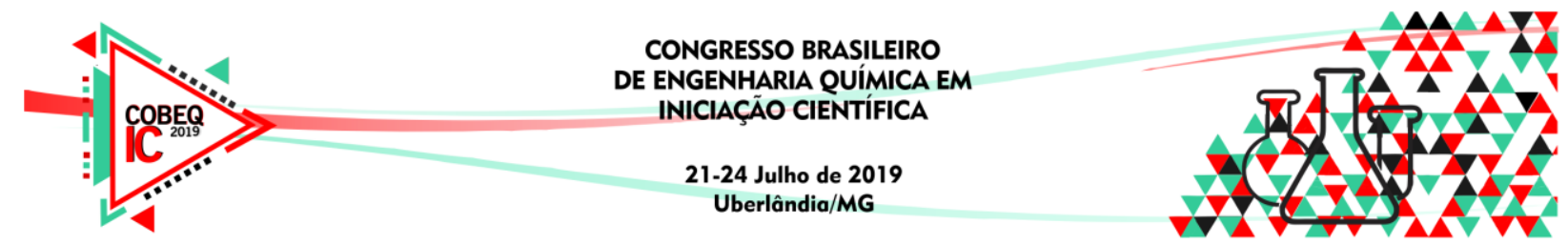

This equation has to be integrated when the system goes from state 1 to state 2 , and from 3 to 4 as well. Assumptions of constant volume heat, average temperature, $B$ and its derivative, also the average values in the range of integrated temperature will be used resulting:

$$
-\frac{C_{v}}{R} \ln \frac{T_{2}}{T_{1}}=-2 \bar{T} \frac{\overline{d B}}{d T}\left(\frac{1}{\left(V_{2}-\bar{B}\right)^{3}}-\frac{1}{\left(V_{1}-\bar{B}\right)^{3}}\right)+\ln \frac{V_{2}-\bar{B}}{V_{1}-\bar{B}}
$$

The second virial coefficient $(B)$ was estimated by Vetere's model (Vetere, 2005):

$$
\frac{B p_{c}}{R T_{c}}=T_{b} B_{b}^{*}\left[\frac{\exp \left\{K\left(T_{b}-T\right)\right\}}{T}\right]
$$

Where $p_{c}, T_{c}$ are the critical pressure and temperature, $T_{b}$ is the boiling temperature, $K$ and $B_{b}^{*}$ are constants for the specific molecule. Critical and normal parameters can be found in Poling et al., 2001 and in Vetere, 2005 as well, including the mixture rules for the associated compounds.

Considering that the combustion air is composed by a mixture of $\mathrm{O}_{2}$ and $\mathrm{N}_{2}$ as the process fluid in the Otto cycle, the second virial of the mixture $\left(B_{M}\right)$ was calculated by the following equation:

$$
B_{M}=\sum_{i=1}^{2} \sum_{j=1}^{2} x_{i} x_{i} B_{i j}
$$

where $i, j$ are the compounds of the binary mixture.

\section{RESULTS AND DISCUSSION}

The effect of temperature in the molar capacity and the use of virial equation are novel approaches applied on the method of engine operating with Otto cycle, both of which are the improved schemes used here. Unlike the traditional Otto cycle, the proposed improvements follow the principle of non-ideal gas and molar capacities changing with temperature.

The four different methodologies of the estimative have been applied on the calculations for gaseous system in the Otto Cycle considering that: ideal or virial gas, constant or variable $\mathrm{k}$ and ambient or heated air. The systems used are: ambient and heated air and the calculated dimensions for the different methodologies are presented in Figures 1-5.

Fig 1. - Effect of initial temperature of the ideal gas in the thermal efficiency as a function of compression ratio. $(\mathbf{\square}-300 \mathrm{~K} ; \bigcirc: 473 \mathrm{~K})$

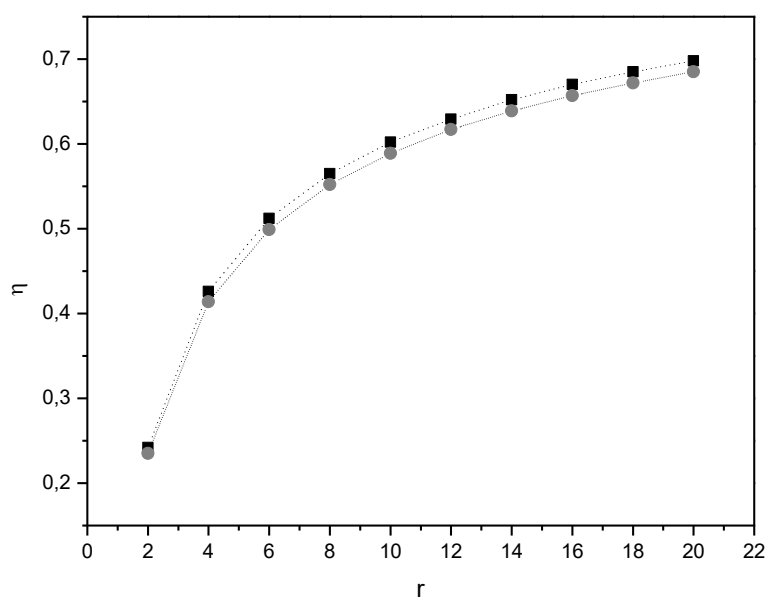




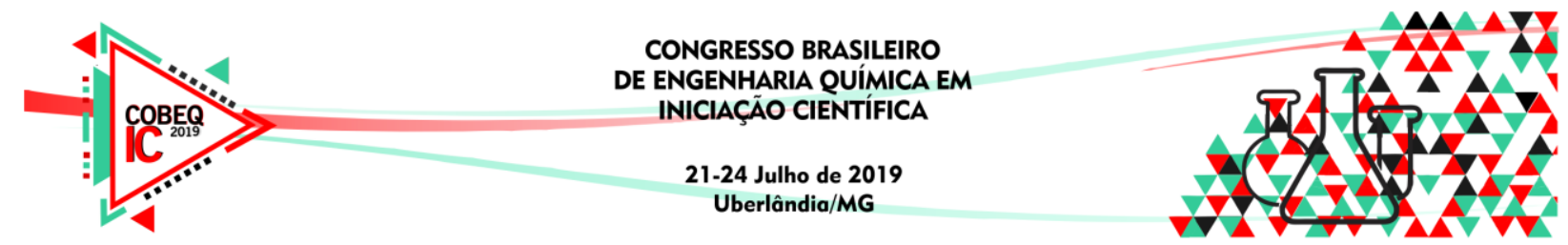

Figures 1-2 illustrate plots of the calculated data for the air system in the different inlet conditions. According to literature heating the inlet air is not recommended for any combustion engine (Potter and Scott, 2007).

Fig. 2 - Comparison the results of average pressure as a function of $r$ for ideal gas at initial temperature of $300(\boldsymbol{\square})$ and $473 \mathrm{~K}(\mathrm{O})$.

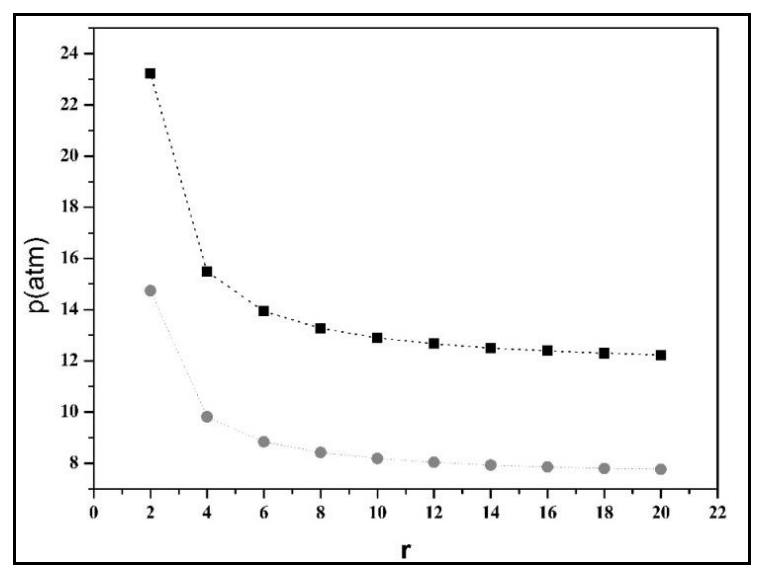

Regarding the influence of variation of the " $k$ " coefficient, all the calculations were repeated and results compared with the later ones. Figure 3 illustrates the high influence of the methodology in the results, and in Figure 4 it can be seen that the temperature of the inlet air has a slight influence in the final results. It is clear that not considering the variation of $\mathrm{k}$ in the engine calculations, can really hiper-estimate the engine project. As it was expected, when the inlet air is heated and the methodology consider the influence of temperature in the $\mathrm{k}$ coefficient, the same behavior and result obtained for ambient air is reached, as we can see in Figure 5. For compression ratio between 8 and 12, around $15 \%$ of variation in the thermal efficiency is observed, showing that the method disregarding the influence of temperature in the $\mathrm{k}$ coefficient is an overestimated result.

Fig 3. - Comparison of influence in the ideal gas thermal efficiency of the cycle when the effect of the temperature is considered in the calculations ( $\square \mathrm{k}$ is constant; $\bigcirc$ : k varies with temperature)

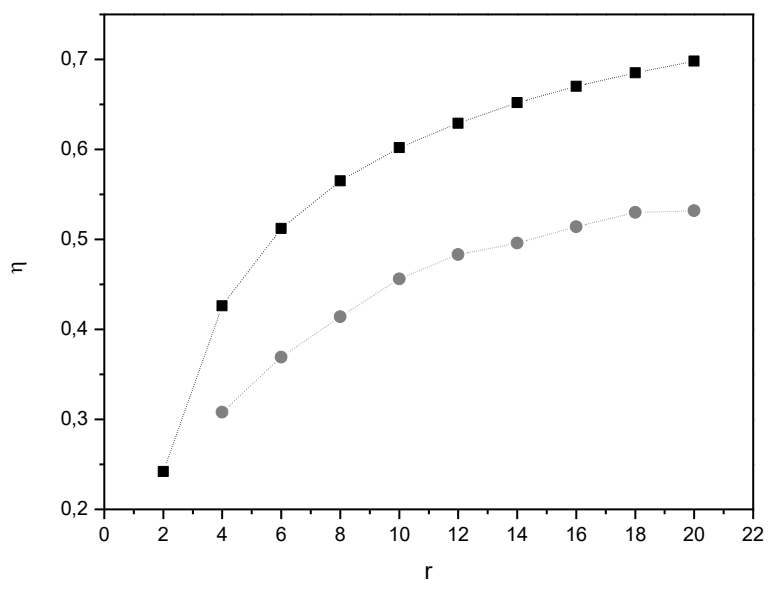




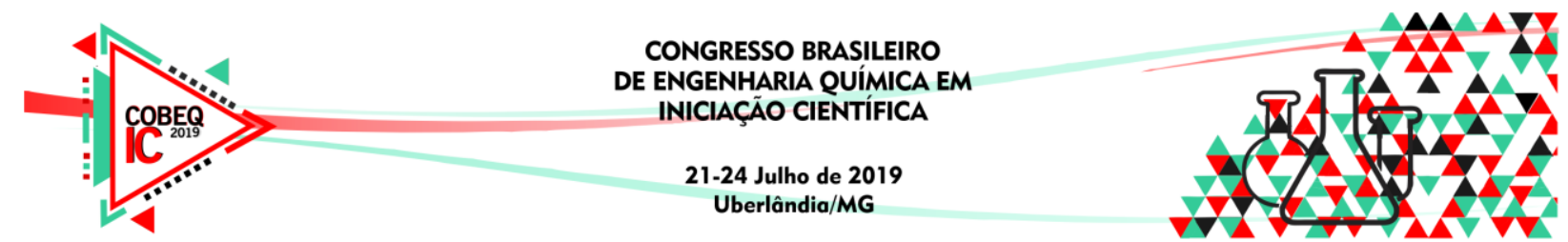

Fig 4. - Comparison of influence in the ideal gas thermal efficiency of the cycle when the effect of the temperature is considered in the calculations of $\underline{c}_{p} \underline{c}_{v_{-}}(\mathbf{\square}:$ air fed at room temperature; $\bigcirc$ : heated air is fed)

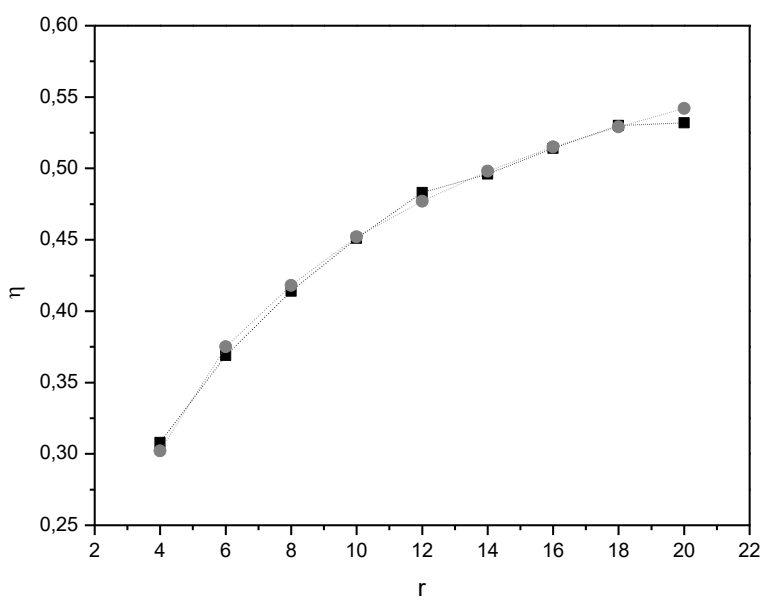

Fig 5. - Comparison of influence in the ideal gas thermal efficiency of the cycle when heated air $\left(200^{\circ} \mathrm{C}\right)$ is fed to the engine . ( $\square \underline{\mathrm{c}_{p}} \underline{\underline{c}}_{\underline{v}}$ is constant; $\bigcirc$ : average $\left.\underline{\mathrm{c}}_{\underline{p}} / \underline{\mathrm{c}}_{\mathrm{v}} \underline{\text { is considered }}\right)$

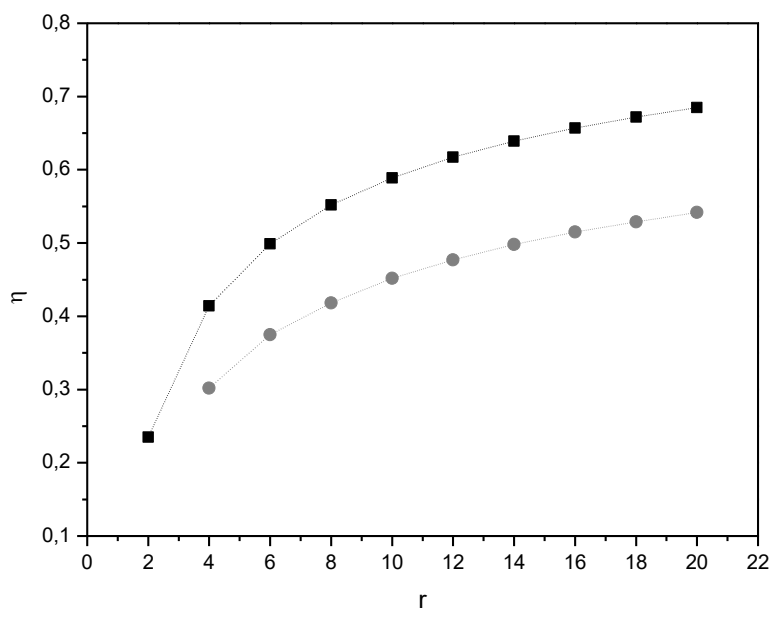

For lower compression rate conditions $(<10)$ both methods have a small deviation in the yield results. Overall, the ideal gas model for heated air performs slightly better than the ambient gas model because it is expected, in real process, lower results for yield because the assumptions that are made when methods are proposed.

\section{CONCLUSIONS}

The following findings were obtained through the present study. 


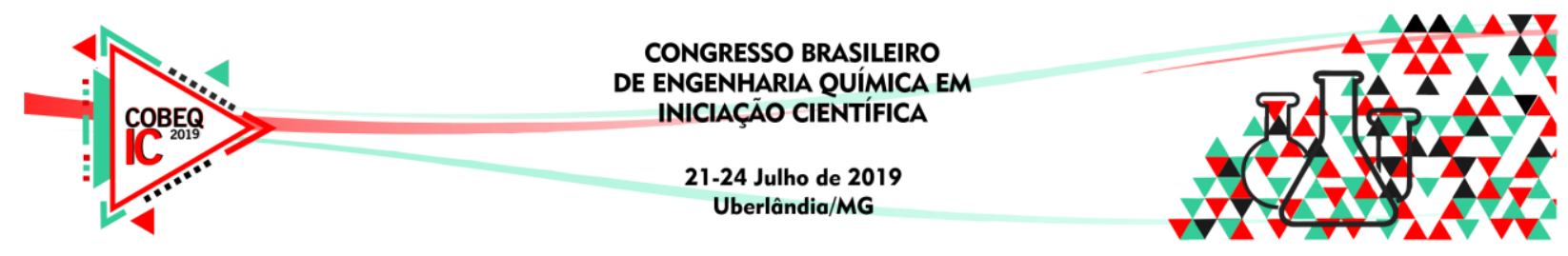

Considering the effect of temperature under $\mathrm{k}$ coefficient markedly cause reducing on thermal efficiency, compared with when this variable was determined by original methodology of Otto Cycle.

Using ideal ou virial equation to represent the pVT gas behavior in the methodologies has not provided substantial variations in the results. The effects were made clear by quantitatively calculating the thermal efficiency and mean pressure near the real conditions of engine working. Also, increasing the temperature of the injected air weakened mean pressure and also lessened the effect on thermal efficiency.

The results also revealed that mean pressure decreased under all conditions, and depending on the inlet temperature of the gas, the value was shorter for the same compression ratio.

\section{ACKNOWLEDGMENTS}

This study was conducted as part of the Mrs Rocha's Project under the direction of the UniRV - PRPI that provided the schollarship grant $2 / 2018$. The authors would like to express their appreciation to everyone involved.

\section{REFERENCES}

BOSCH, R. Automotive handbook. $5^{\text {th }}$ ed. Bentley Publishers; 2000.

CHIGIER, N. A. Energy, combustion and the environment. New York: McGraw Hill; 1981.

GUIBET J-C. Fuels and engines. Technology. Energy environment, 2 vols. Paris, France: Technip; 1999.

HEYWOOD, J. B. The internal combustion engine fundamentals. New York: McGraw-Hill; 1988.

LUMLEY, J. L. Engines: an introduction. Cambridge, UK: Cambridge University Press; 1999.

POTTER, M. C., SCOTT, E. P., Ciências Térmicas - Termodinâmica, Mecânica dos Fluidos e Transmissão de Calor - Thomson Learning, 2007 - São Paulo.

POLING, B. E.; PRAUSNITZ, J. M.; O'CONNELL, J. P.. The properties of gases and liquids $5^{\text {th }}$ ed. McGraw-Hill, $2001-768$ pgs

US Department of Energy. www.doe.gov. Accessed July 20, 2018.

VETERE, A.. An improved method to predict second cross virial coefficients. Fluid Phase Equilib. v. 230, p. 15-20, 2005.

ZHAO, F.; LAI, M-C; HARRINGTON, D. L., Automotive spark-ignited direct-injection gasoline engines. Prog. Energy Combust. Sci., v.25, p. 437-562, 1999. 